\title{
Artigo Original / Original Paper \\ Palinologia de espécies de Grewioideae (Malvaceae sensu lato) ocorrentes no estado do Rio de Janeiro, Brasil
}

\author{
Palynology of Grewioideae species (Malvaceae sensu lato) occurring in the state \\ of Rio de Janeiro, Brazil
}

\author{
Vanessa Holanda Righetti de Abreu ${ }^{1,3,4}$, Gabrielle Reboredo Menezes Vieira ${ }^{2}$, \\ Raquel Maria Baptista Souza de Souza ${ }^{2}$ \& Vania Gonçalves-Esteves ${ }^{2}$
}

\begin{abstract}
Resumo
O objetivo desse estudo foi caracterizar a morfologia polínica das espécies de Grewioideae ocorrentes no estado do Rio de Janeiro. Grãos de pólen de 12 espécies foram examinados: tribo Apeibeae (Apeiba tibourbou, Corchorus hirsutus, Triumfetta althaeoides, T. grandiflora, T. obscura, T. rhomboidea) e tribo Grewieae (Luehea candicans, L. conwentzii, L. divaricata, L. grandiflora, L. ochrophylla, L. paniculata). Os grãos de pólen foram acetolisados, medidos, descritos e ilustrados sob microscopia de luz (ML). Para observar detalhes da superfície e abertura, grãos de pólen não acetolisados foram analisados em microscópio eletrônico de varredura $(\mathrm{MEV})$ e, posteriormente, eletromicrografados. Foram caracterizados os grãos de pólen quanto à forma, ao tamanho, ao tipo de abertura, à polaridade e à constituição da exina. As espécies analisadas possuem grãos de pólen médios a grandes, isopolares, peroblatos a prolatos, 3-cólporos e sexina reticulada. Na chave polínica, a maioria das espécies pôde ser separada pelos atributos palinológicos. Isso permite considerar que as espécies aqui estudadas são euripolinícas, uma vez que é possível reconhecer a maioria das espécies pelas características palinológicas. Acredita-se que, o presente estudo fornece dados polínicos que podem auxiliar na identificação das espécies de Grewioideae que ocorrem no estado do Rio de Janeiro.
\end{abstract}

Palavras-chave: grãos de pólen, Malvales, morfologia polínica.

\begin{abstract}
The objective of this study was to characterize the pollen morphology of the Grewioideae species occurring in the state of Rio de Janeiro. Pollen grains of 12 species were examined: tribe Apeibeae (Apeiba tibourbou, Corchorus hirsutus, Triumfetta althaeoides, T. grandiflora, T. obscura, T. rhomboidea) and tribe Grewieae (Luehea candicans, L. conwentzii, L. divaricata, L. grandiflora, L. ochrophylla, L. paniculata). The pollen grains were acetolysed, measured, described and illustrated under light microscopy (LM). To observe the surface and opening, pollen grains not acetolysed were analyzed in scanning electron microscope (SEM) and subsequently eletromicrographs. Were characterized pollen grains as the shape, size, opening type, the polarity and the exina constitution. The analyzed species have pollen grains medium to large, isopolar, peroblate to prolate, 3-colporate and reticulated sexine. In pollen key, most species could be separated those attributes palynological. It allows consider that species which were studied here are euripolinic, since it is possible to recognize most species by palynological characteristics. It is believed that the present study provides pollen characteristics data that may help identify the species of Grewioideae that occur in the State of Rio de Janeiro. Key words: pollen grains, Malvales, pollen morphology.
\end{abstract}

\footnotetext{
${ }^{1}$ Universidade Federal do Oeste do Pará - UFOPA, Inst. Biodiversidade e Florestas - IBEF, Lab. de Botânica e Palinologia (LABOP), R. Vera Paz s/n (Unidade Tapajós), Bairro Salé, 68040-255, Santarém, PA, Brasil.

${ }^{2}$ Universidade Federal do Rio de Janeiro, Museu Nacional, Depto. Botânica, Lab. Palinologia, Quinta da Boa Vista, São Cristóvão, 20940-040, Rio de Janeiro, RJ, Brasil.

${ }^{3}$ ORCID: <https://orcid.org/0000-0002-2989-3151>

${ }^{4}$ Autor para correspondência: vanessahra@yahoo.com.br
} 


\section{Introdução}

A ordem Malvales Juss. ex Bercht. \& J. Presl compreende 10 famílias, entre elas Malvaceae Juss., que destaca-se por sua diversidade, com cerca de 4.200 espécies distribuídas em todo o mundo, principalmente nas regiões tropicais (APG III 2009; APG IV 2016).

Os estudos filogenéticos realizados com Malvaceae s.l., segundo Bayer et al. (1999) e Alverson et al. (1999), mostraram nove clados como subfamílias: Bombacoideae Burnett, Brownlowioideae Burret, Byttnerioideae Burnett, Dombeyoideae Beilschmied, Grewioideae Hochreutiner, Helicterioideae Meisner, Malvoideae Burnett, Sterculioideae Beilschmied e Tilioideae Arnott.

As subfamílias Grewioideae e Byttnerioideae formam a primeira linhagem a se divergir; Grewioideae compreende ca. 700 espécies e 25 gêneros distribuídos em regiões tropicais do Novo e do Velho Mundo e inclui principalmente a maioria dos gêneros da antiga família Tiliaceae (Bayer et al. 1999; Bayer \& Kubitzki 2003; Brunken \& Muellner 2012).

Segundo Perveen \& Qaiser (2007) e Brunken \& Muellner (2012), Grewioideae possui espécies com as seguintes características: as sépalas não possuem nectários na base ventral, os nectários são presentes nas bases das pétalas ou androginóforos; possui numerosos estames (ditecas), muitas vezes livres. Em contraste, Byttnerioideae apresenta estaminódios que ocorrem exclusivamente na periferia de um androécio fértil.

De acordo com Brunken \& Muellner (2012), Grewioideae está subdividida em dois clados bem suportados que são baseados em análises moleculares e caracteres morfológicos, Apeiba e Grewia. Os autores recomendam classificar os clados como tribos, Apeibeae Benth. e Grewieae Endl. As espécies que foram levantadas nesse estudo em todos os herbários do Rio de Janeiro, são aquelas ocorrentes no estado do Rio de Janeiro e pertencem a ambas as tribos, sendo as espécies do gênero Apeiba, Corchorus e Triumfetta pertencentes à tribo Apeibeae e as espécies do gênero Luehea pertencentes à tribo Grewieae.

De acordo com Alverson et al. (1999), os resultados encontrados para o núcleo das Malvales devem ser comparados e combinados com dados de outros genes, bem como com dados morfológicos. Como declarado por Judd \& Manchester (1997) a delimitação de famílias dentro do núcleo de
Malvales é problemática, e isso vem sendo discutido por sistematas há muito tempo.

Portanto, compreende-se que uma análise palinológica das espécies ocorrentes no estado do Rio de Janeiro, pode auxiliar estudos taxonômicos e filogenéticos. Logo, o objetivo desse estudo foi caracterizar a morfologia polínica das espécies de Grewioideae que ocorrem no estado do Rio de Janeiro.

\section{Material e Métodos}

Grãos de pólen de 12 espécies de Grewioideae que ocorrem no estado do Rio de Janeiro - Brasil foram examinados: tribo Apeibeae (Apeiba tibourbou Aubl., Corchorus hirsutus L., Triumfetta althaeoides Lam., T. grandiflora Vahl, T. obscura A. St.-Hil., T. rhomboidea Jacq.) e tribo Grewieae (Luehea candicans Mart., L. conwentzii K. Schum., L. divaricata Mart., L. grandiflora Mart., L. ochrophylla Mart., L. paniculata Mart.).

As amostras foram obtidas a partir de anteras de botões florais maduros de espécimes depositados no Herbário Alberto Castellanos (GUA); Herbarium Bradeanum (HB); Herbário do Museu Nacional da Universidade Federal do Rio de Janeiro (R); Instituto de Pesquisas Jardim Botânico do Rio de Janeiro (RB); Herbário da Universidade Federal Rural do Rio de Janeiro (RBR).

Foram medidos, sempre que possível, até três espécimes de cada espécie com a finalidade de se estabelecer à variação morfométrica dos espécimes. Para o estudo sob microscópio de luz, o material polínico foi preparado segundo o método da acetólise preconizado por Erdtman (1952) com modificações propostas por Melhem et al. (2003). De cada espécie, foram utilizadas anteras de, no mínimo, dois botões florais, por espécime, visando obter uma amostra representativa da espécie (Salgado-Labouriau et al. 1965). Os grãos de pólen acetolisados foram montados em gelatina glicerinada de Kisser (1935 apud Erdtman 1952).

Do material padrão foram mensurados dois diâmetros em grãos de pólen apolares; nos grãos de pólen isopolares foram medidos, em vista equatorial o diâmetro polar e o equatorial. Foram tomadas, aleatoriamente, 25 medidas dos diâmetros, distribuídas em um mínimo de três lâminas, de modo a uniformizar a amostra (Salgado-Labouriau et al. 1965). Foram calculados a média aritmética (x), o desvio padrão da amostra (s); o desvio padrão da média (s); o coeficiente de variabilidade (CV\%) e o intervalo de confiança a 95\% (I.C). As medidas foram reunidas em forma de tabelas (Tabs. 1-4). 
Foram realizadas 10 medidas e calculada a média aritmética das dimensões das aberturas e da espessura da exina, dos diâmetros equatorial em vista polar (DEVP) e do lado do apocolpo (LA) nos grãos de pólen isopolares e dos diâmetros do material de comparação.

As medidas do material polínico acetolisado foram efetuadas no prazo máximo de uma semana, a fim de se evitar possíveis alterações no tamanho e na forma dos grãos de pólen (Salgado-Labouriau 1973).

Os grãos de pólen acetolisados e preparados para exame em microscopia de luz foram fotografados em fotomicroscópio Zeiss Axiostar plus equipado com câmera digital Canon PC 1089 e as fotomicrografias foram organizadas em forma de prancha com auxílio do programa Corel Draw 12.

A terminologia utilizada para a descrição da morfologia polínica quanto ao tamanho, a forma, o número de aberturas e o padrão de ornamentação da sexina está de acordo com Barth \& Melhem (1988), Punt et al. (2007) e Hesse et al. (2009).

Sob microscópio estereoscópio as anteras do material herborizado foram retiradas com pinças esterilizadas, esmagadas e os grãos de pólen não acetolisados, espalhados pela superfície da fita dupla-face de carbono, que recobre os suportes de alumínio devidamente numerados. As amostras foram metalizadas com uma fina camada de ouro paládio (ca. de $150^{\circ} \mathrm{A}$ de espessura) por três minutos, sendo posteriormente analisadas em aparelho Zeiss DS M960 no Laboratório de Ultraestrutura Celular do Instituto de Biofísica da Universidade Federal do Rio de Janeiro e em aparelho Jeol, JSM 6390 do Departamento de Invertebrados do Museu Nacional, Universidade Federal do Rio de Janeiro.

Foram confeccionados palinogramas com imagens obtidas tanto em microscópio de luz, quanto eletrônico de varredura, registrando, sempre que possível, as vistas polares e equatoriais em grãos de pólen isopolares, aspecto geral nos grãos de pólen apolares e detalhe da superfície.

\section{Resultados}

Grewioideae Dippel.

1. Apeiba tibourbou Aubl. Fig. 1a-b

Grãos de pólen médios, isopolares, suboblatos, área polar pequena (Tabs. 1; 3), âmbito subcircular, 3-colporados, diploporados (Fig. 1ab), colpos longos, estreitos, sem margem aparente, membrana ornamentada, duas endoaberturas nitidamente lalongadas (Fig. 1a-b; Tab. 4), sexina reticulada, heterobrocada, muros largos, baixos, sinuosos, com grânulos nos pontos de interseção dos muros; lúmen com ornamentação. Nexina mais espessa do que a sexina (Tab. 4). Não foi possível conseguir espécime para comparação.

\section{Corchorus hirsutus L.}

Fig. 1c-d

Grãos de pólen médios, isopolares, prolatos, área polar pequena (Tabs. 1;3), âmbito subtriangular, 3-colporados (Fig. 1c), colpos longos, estreitos, sem margem aparente, membrana ornamentada (Fig. 1d), endoabertura nitidamente lalongada (Tab. 4), sexina reticulada, heterobrocada, muros largos, baixos, sinuosos, com lúmen recoberto por fina camada de sexina densamente perfurada. Nexina mais espessa do que a sexina (Tab. 4).

Os espécimes utilizados para comparação apresentaram apenas os valores da faixa de variação do diâmetro polar dentro dos limites quando comparados com o material padrão. A forma se manteve constante.

\section{Luehea Willd.}

Figs. 1e-1; 2a-d

Grãos de pólen médios e grandes, isopolares na maioria das espécies, oblato-esferoidais, prolatos, subprolatos ou prolato-esferoidais, área polar pequena, âmbito subtriangular, 3-colporados, colpos longos, estreitos, como ou sem margen aparente, membrana ornamentada ou psilada, endoabertura lalongada, sexina perfurada a microrreticulada no apocolpo ou sexina reticulada em toda a superficie, muros retos ou sinuosos, largos ou estreitos, baixos ou altos, lisos ou com gránulos nos pontos de interseção dos muros, lumens com ou sem ornamentação, quando presentes, recobertos por fina camada de sexina densamente perfurada ou com microrretículo no interior das malhas. Nexina ligeiramente mais espessa ou com a mesma espessura da sexina.

\subsection{Luehea candicans Mart.}

Fig. 1e-f

Grãos de pólen grandes, isopolares, prolatos a subprolatos, área polar pequena (Tabs. $1 ; 3$ ), âmbito subtriangular, 3-colporados (Fig. 1e), colpos longos, estreitos, margem não aparente, membrana ornamentada (Fig. 1f), endoabertura nitidamente lalongada (Fig. 1f; Tab. 4), sexina perfurada a microrreticulada no apocolpo (Fig. 1e) e reticulada, heterobrocada no mesocolpo, muros lisos, retos, baixos, com perfurações, lúmen recoberto por fina camada de sexina densamente perfurada; lumens reduzem de dimensão próximo 

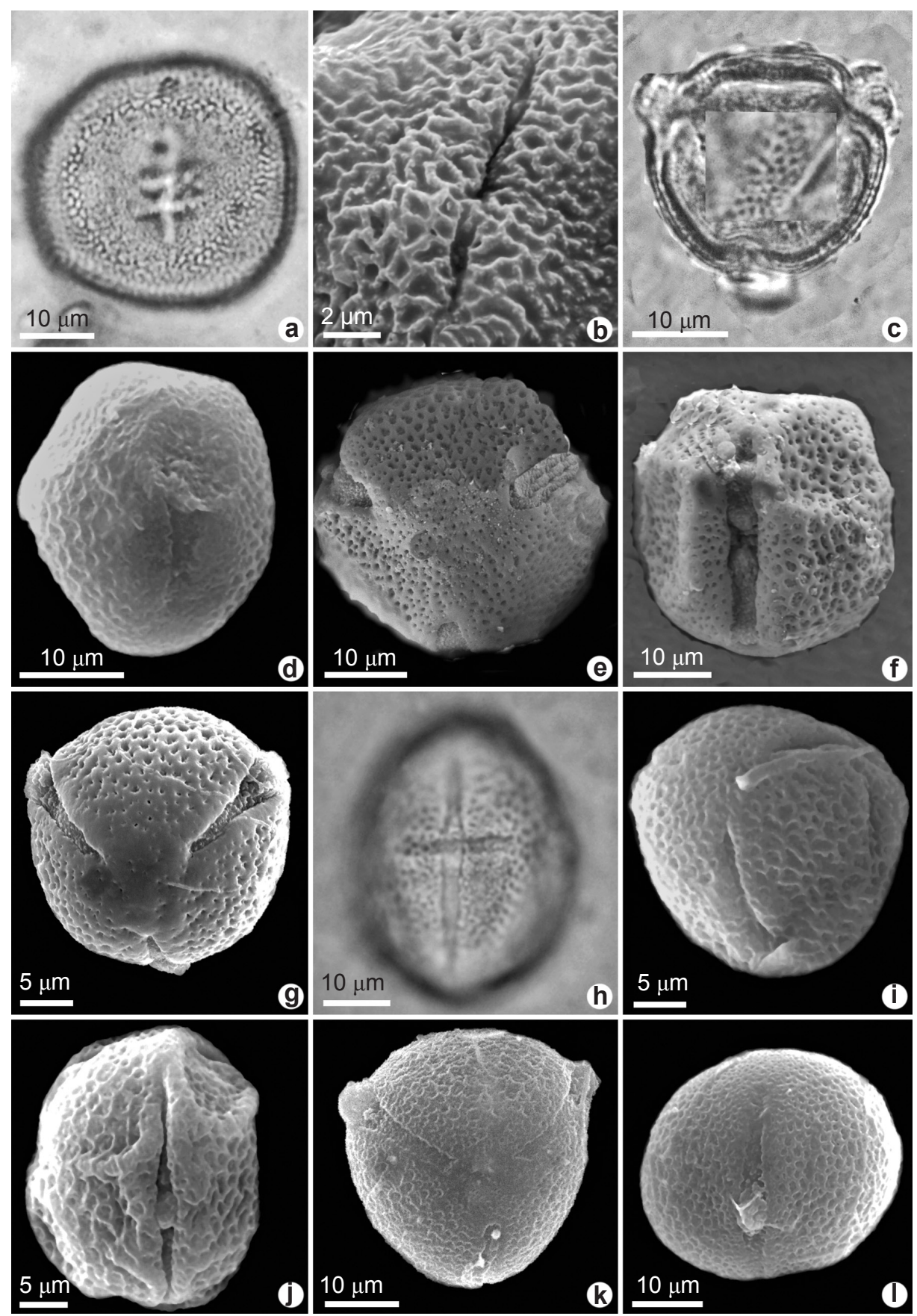

Figura 1 -Fotomicrografias e eletromicrografias de grãos de pólen de espécies de Grewioideae. a-b Apeiba tibourbou - vista equatorial: a. abertura (ML); b. detalhe da abertura (MEV). c-d Corchorus hirsutus - vista polar: c. corte óptico (ML); vista equatorial: d. abertura (MEV). e-f Luehea candicans - e. vista polar: aspecto geral (MEV); vista equatorial: f. abertura (MEV). g-h L. conwentzii - vista polar: g. aspecto geral (MEV); vista equatorial: h. abertura (ML). i-j L. divaricata - vista polar: i. aspecto geral (MEV); vista equatorial: j. abertura (MEV). $\mathrm{k}-1$ L. grandiflora - vista polar: k. aspecto geral (MEV); vista equatorial: 1. abertura (MEV).

Figure 1 - Photomicrographs and electron micrographs of Grewioideae species of pollen grains. a-b Apeiba tibourbou - equatorial view: a. opening (LM); b. detail of the opening (SEM). c-d Corchorus hirsutus - polar view: c. optical cross-section (LM); equatorial view: d. opening (SEM). e-f Luehea candicans - e. polar view: general view (SEM); equatorial view: f. opening (SEM). g-h L. conwentzii polar view: g. general view (SEM); equatorial view: h. opening (LM). i-j L. divaricata - polar view: i. general view (SEM); equatorial view: j. opening (SEM). k-1 L. grandiflora - polar view: k. general view (SEM); equatorial view: 1. opening (SEM). 
Tabela 1 - Medidas (em $\mu \mathrm{m}$ ) dos grãos de pólen em vista equatorial: diâmetro polar (DP); diâmetro equatorial (DE); média aritmética $(\overline{\mathrm{x}})$; desvio padrão da média $\left(\mathrm{s}_{\mathrm{X}^{-}}\right)$e intervalo de confiança (IC 95\%) de espécies de Grewioideae $(\mathrm{n}=25) ;(* \mathrm{n}<25)$.

Table 1 - Measures (in $\mu \mathrm{m}$ ) of pollen grains in equatorial view: polar diameter (DP); equatorial diameter (DE); arithmetic average ( $\overline{\mathrm{x}}$; mean standard deviation $\left(\mathrm{s}_{\mathrm{x}}{ }^{-}\right)$and confidence intervals (IC 95\%) Grewioideae species $(\mathrm{n}=25) ;\left(*_{\mathrm{n}}<25\right)$.

\begin{tabular}{|c|c|c|c|c|c|c|c|c|}
\hline \multirow[t]{2}{*}{ Espécies } & \multicolumn{3}{|c|}{ Diâmetro polar } & \multicolumn{3}{|c|}{ Diâmetro equatorial } & \multirow[t]{2}{*}{$\mathbf{P} / \mathbf{E}$} & \multirow[t]{2}{*}{ Forma } \\
\hline & $\begin{array}{l}\text { Faixa de } \\
\text { variação }\end{array}$ & $\mathbf{x}^{-} \pm \mathbf{s}_{\mathbf{x}^{-}}$ & IC 95\% & $\begin{array}{l}\text { Faixa de } \\
\text { variação }\end{array}$ & $\mathbf{x}^{-} \pm \mathbf{s}_{\mathbf{x}^{-}}$ & IC 95\% & & \\
\hline Apeiba tibourbou * & $32,5-40,0$ & 34,9 & ---- & $37,5-45,0$ & 41,3 & --- & 0,84 & suboblata \\
\hline Corchorus hirsutus & $37,5-45,0$ & $40,0 \pm 0,3$ & $39,4-40,6$ & $22,5-27,5$ & $24,9 \pm 0,3$ & $24,3-25,5$ & 1,60 & prolata \\
\hline Luehea candicans & $49,5-52,5$ & 50,7 & --- & $40,0-45,0$ & 42,5 & ---- & 1,19 & subprolata \\
\hline L. conwentsii $*$ & $42,5-50,0$ & $46,3 \pm 0,5$ & $45,3-47,3$ & $27,5-35,0$ & $30,9 \pm 0,4$ & $30,1-31,7$ & 1,50 & prolata \\
\hline L. divaricata & $35,0-45,0$ & $39,0 \pm 0,4$ & $38,1-39,9$ & $30,0-37,5$ & $35,1 \pm 0,3$ & $34,3-35,8$ & 1,11 & prolato-esferoidal \\
\hline L. grandiflora * & $50,0-55,0$ & 51,5 & --- & $42,5-50,0$ & 45,8 & ---- & 1,12 & prolato-esferoidal \\
\hline L. ochrophylla & $38,8-46,3$ & $43,2 \pm 0,4$ & $42,4-44,0$ & $27,5-35,0$ & $31,7 \pm 0,4$ & $30,9-32,5$ & 1,36 & prolata \\
\hline L. paniculata & $40,0-50,0$ & $43,9 \pm 0,5$ & $42,9-45,0$ & $27,5-35,0$ & $31,8 \pm 0,4$ & $31,0-32,6$ & 1,38 & prolata \\
\hline Triunfetta althaeoides & $60,0-67,5$ & $64,7 \pm 0,5$ & $63,7-65,7$ & $32,5-41,3$ & $37,4 \pm 0,5$ & $36,4-38,4$ & 1,73 & prolata \\
\hline T. grandiflora & $57,5-65,0$ & $61,8 \pm 0,4$ & $61,0-62,6$ & $37,5-47,5$ & $43,3 \pm 0,5$ & $42,3-44,3$ & 1,43 & prolata \\
\hline T. obscura & $45,0-52,5$ & $49,5 \pm 0,3$ & $48,9-50,1$ & $35,5-42,5$ & $38,7 \pm 0,4$ & $38,0-39,4$ & 1,28 & subprolata \\
\hline T. rhomboidea & $37,5-45,0$ & $40,7 \pm 0,5$ & $39,7-41,7$ & $20,0-27,5$ & $23,7 \pm 0,4$ & $22,9-24,5$ & 1,72 & prolata \\
\hline
\end{tabular}

das aberturas. Nexina ligeiramente mais espessa do que a sexina (Tab. 4).

O espécime utilizado para comparação apresentou apenas os valores do diâmetro polar dentro dos limites quando comparados com o material padrão. A forma também variou.

\subsection{Luehea conwentzii K. Schum. Fig. 1g-h}

Os grãos de pólen são médios, isopolares, prolatos, área polar pequena (Tabs. 1; 3), âmbito subtriangular, 3-colporados (Fig. 1g), colpos longos, estreitos, margem psilada (Fig. 1g), membrana ornamentada, endoabertura nitidamente lalongada (Tab. 4), sexina no apocolpo perfurada, no mesocolpo, reticulada, heterobrocada, com muros largos, retos, baixos, lisos, apresentando perfurações e lúmen recoberto por fina camada de sexina densamente perfurada e, em alguns, com ornamentação. Nexina ligeiramente mais espessa do que a sexina (Tab. 4).

Os espécimes utilizados para comparação apresentaram apenas os valores da faixa de variação do diâmetro equatorial dentro dos limites quando comparados com o material padrão. A forma se manteve constante.

\subsection{Luehea divaricata Mart.}

Fig. 1i-j

Grãos de pólen médios, isopolares, prolatoesferoidais, área polar pequena (Tabs. 1;3), âmbito subtriangular, 3-colporados (Tab. 4), colpos longos, estreitos, com costa, margem espessa, ornamentada, membrana ornamentada (Fig. 1i-j), endoabertura nitidamente lalongada, a ornamentação da sexina é reticulada, heterobrocada, com muros largos, retos, baixos, lisos, com lúmen recoberto por fina camada de sexina densamente perfurada; os lumens reduzem de diâmetro no apocolpo (Fig. 1i). Nexina ligeiramente mais espessa do que a sexina (Tab. 4). Não foi possível conseguir espécime para comparação.

\subsection{Luehea grandiflora Mart.}

Fig. 1k-1

Grãos de pólen grandes, isopolares, oblatoesferoidais a prolato-esferoidais, área polar pequena (Tabs. 1; 3), âmbito subtriangular, 3-colporados (Fig. 1k), colpos longos, estreitos, com costa, margem fina, psilada, membrana ornamentada (Fig. 11), endoabertura nitidamente lalongada (Tab. 4), sexina perfurada no apocolpo, no mesocolpo é reticulada, heterobrocada, com muros largos, lisos, retos, baixos, com perfurações, 
Tabela 2 - Medidas (em $\mu \mathrm{m}$ ) dos grãos de pólen polares, em vista polar: diâmetro equatorial (DEVP); lado do apocolpo (LA) e índice da área polar (IAP) de espécies de Grewioideae $(\mathrm{n}=10)$.

Table 2 - Measurements (in $\mu \mathrm{m}$ ) of polar pollen grains in polar view: equatorial diameter (DEVP); apocolpo side (LA) and the polar area index (IAP) Grewioideae species $(\mathrm{n}=10)$.

\begin{tabular}{lcccccccc}
\hline \multirow{2}{*}{ Espécies } & \multicolumn{2}{c}{ DEVP } & & \multicolumn{2}{c}{ LA } & & \multicolumn{2}{c}{ Área polar } \\
\cline { 2 - 3 } & Faixa de variação & $\mathbf{x}^{-}$ & & Faixa de variação & $\mathbf{x}^{-}$ & & IAP & \\
\hline Apeiba tibourbou & $36,3-42,5$ & 38,2 & $17,5-20,0$ & 18,8 & & 0,49 & pequena \\
Corchorus hirsutus & $22,5-26,3$ & 24,5 & $2,5-7,5$ & 6,3 & & 0,26 & pequena \\
Luehea candicans & $42,5-45,0$ & 44,4 & $10,0-17,5$ & 13,1 & 0,30 & pequena \\
L. conwentsii & $28,8-32,5$ & 31,1 & $7,5-12,5$ & 10,3 & 0,33 & pequena \\
L. divaricata & $34,5-40,0$ & 37,1 & $7,5-12,5$ & 10,8 & 0,29 & pequena \\
L. grandiflora & $42,5-50,0$ & 46,0 & $10,0-18,8$ & 14,4 & 0,31 & pequena \\
L. ochrophylla & $32,5-37,5$ & 34,7 & $7,5-12,5$ & 10,3 & 0,29 & pequena \\
L. paniculata & $30,0-42,5$ & 34,5 & $7,5-12,5$ & 9,5 & 0,28 & pequena \\
Triunfetta althaeoides & $37,5-42,5$ & 40,0 & $12,5-15,0$ & 13,8 & 0,34 & pequena \\
T. grandiflora & $42,5-52,5$ & 47,5 & $10,0-13,8$ & 11,9 & 0,25 & pequena \\
T. obscura & $37,5-43,0$ & 40,2 & $10,0-17,5$ & 13,0 & 0,32 & pequena \\
T. rhomboidea & $25,0-32,5$ & 28,3 & $5,0-10,0$ & 8,0 & 0,28 & pequena \\
\hline
\end{tabular}

com lúmen recoberto por fina camada de sexina densamente perfurada. Nexina tão espessa quanto à sexina (Tab. 4).

O espécime utilizado para comparação apresentou apenas os valores da faixa de variação e do intervalo de confiança do diâmetro polar dentro dos limites quando comparados com o material padrão. A forma também variou.

\subsection{Luehea ochrophylla Mart.}

Fig. 2a-b

Grãos de pólen médios, isopolares, prolatos, área polar pequena (Tabs. 1; 3), âmbito subtriangular, 3-colporados (Fig. 2a), colpos longos, estreitos, margem não aparente, membrana ornamentada (Fig. 2b), endoabertura nitidamente lalongada (Tab. 4), sexina reticulada, heterobrocada, muros altos, largos, sinuosos, lisos, com perfurações, lumens amplos, recobertos por fina camada de sexina densamente perfurada. Nexina ligeiramente mais espessa que a sexina (Tab. 4). Não foi possível conseguir espécime para comparação.

\subsection{Luehea paniculata Mart.}

Fig. 2c-d

Grãos de pólen médios, isopolares, prolatos, área polar pequena (Tabs. 1;3), âmbito subtriangular, 3-colporados (Fig. 2c), colpos longos, estreitos, margem não aparente, membrana ornamentada, endoabertura lalongada (Tab. 4), sexina reticulada, heterobrocada, muros largos, retos, baixos, lumens amplos, recobertos por fina camada de sexina perfurada e em alguns lúmens são observados pilos (Fig. 2c). Nexina ligeiramente mais espessa do que a sexina (Tab. 4).

Os espécimes utilizados para comparação apresentaram, na maioria valores da faixa de variação e do intervalo de confiança do diâmetro polar e apenas a faixa de variação do diâmetro equatorial dentro dos limites quando comparados com o material padrão. A forma se manteve constante.

\section{Triumfetta L.}

Fig. 2e-1

Grãos de pólen médios a grandes, isopolares, prolatos a subprolatos, área polar pequena (Tabs. 1; 3), âmbito subtriangular, 3-colporados (Fig. 2e), colpos longos, estreitos ou largos, margem fina ou sem margem aparente, membrana ornamentada ou não, endoabertura nitidamente lalongada (Tab. 4), sexina reticulada, heterobrocada, muros estreitos, retos, lisos, altos ou baixos, com ou sem perfurações, lumens pequenos sem ornamentação ou amplos, recobertos por fina camada de sexina densamente perfurada ou com microrretículo no interior das malhas. Nexina tão espessa quanto sexina ou ligeiramente mais espessa (Tab. 4). 

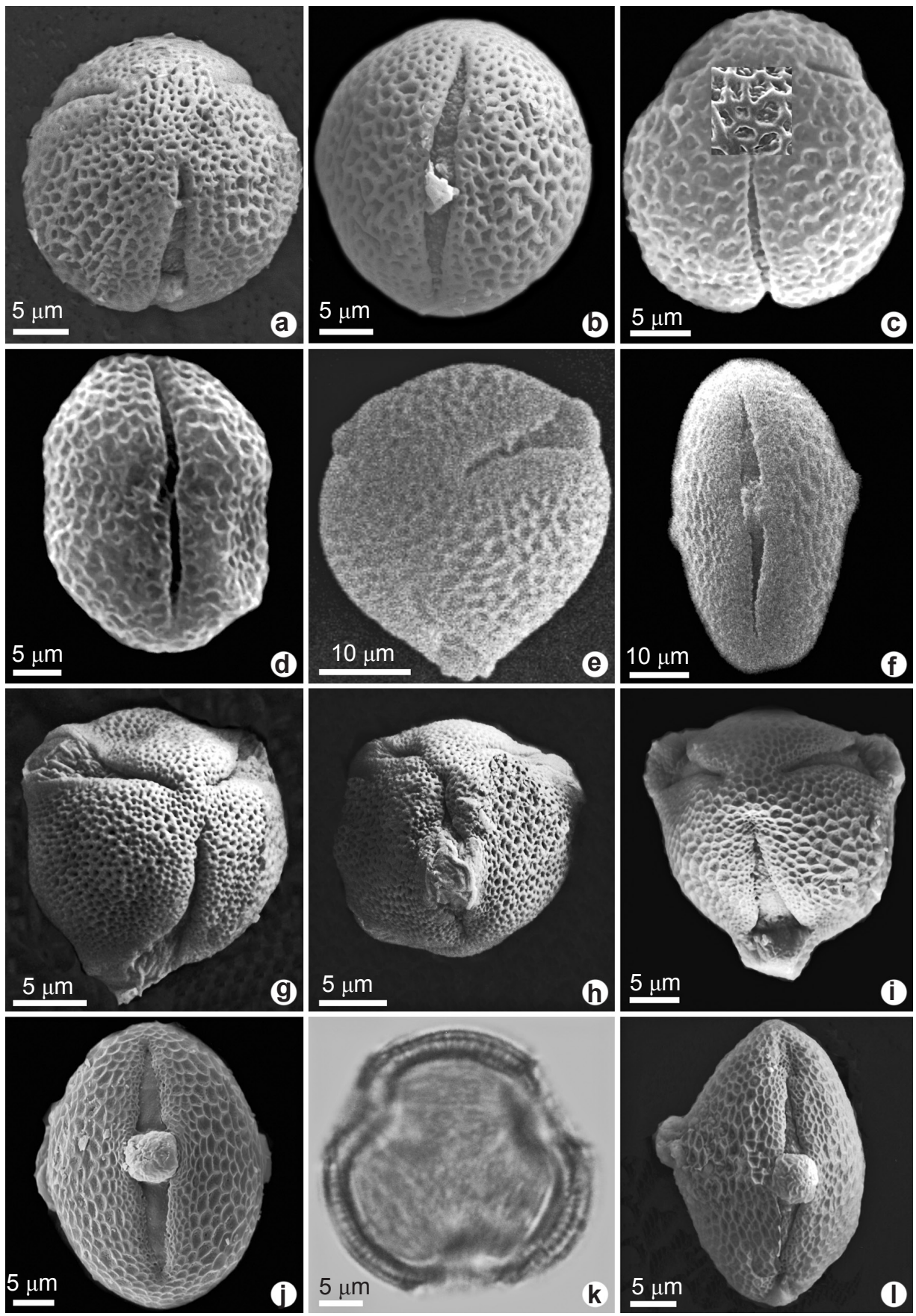

Figura 2 - Fotomicrografias e eletromicrografias de grãos de pólen de espécies de Grewioideae. a-b Luehea ochrophylla - a. vista polar: aspecto geral (MEV); vista equatorial: b. abertura (MEV). c-d L. paniculata - c. vista polar: aspecto geral (MEV); vista equatorial: d. abertura (MEV). e-f Triumfetta althaeoides - e. vista polar (MEV); vista equatorial: f. abertura (MEV). g-h T. grandiflora - vista polar: g. aspecto geral (MEV); vista equatorial: h. abertura (MEV). $\mathrm{i}-\mathrm{j}$ T. obscura - vista polar: i. aspecto geral (MEV); vista equatorial: j. abertura (MEV). k-1 T. rhomboidea - k. vista polar: corte óptico (ML); vista equatorial: 1. abertura (MEV).

Figure 2 - Photomicrographs and electron micrographs of Grewioideae species of pollen grains. a-b Luehea ochrophylla - a. polar view: general view (SEM); equatorial view: b. opening (SEM). L. paniculata c $-\mathrm{d}-\mathrm{c}$. polar view: general view (SEM); equatorial view: d. opening (SEM). e-f Triumfetta althaeoides - e. polar view (SEM); equatorial view: f. opening (SEM). g-h T. grandiflora - polar view: g. general view (SEM); equatorial view: h. opening (SEM). i-j T. obscure - polar view: i. general appearance (SEM); equatorial view: j. opening (SEM). T. rhomboidea $\mathrm{k}-1$ - k. polar view: optical cross-section (LM); equatorial view: 1. opening (SEM). 
Tabela 3 - Medidas (em mm) das aberturas e das camadas da exina dos grãos de pólen de espécies de Grewioideae $(\mathrm{n}=10)$.

Table 3 - Measurements (in mm) of apertures and exine layers of pollen grains Grewioideae species $(n=10)$.

\begin{tabular}{|c|c|c|c|c|c|c|c|}
\hline \multirow[t]{2}{*}{ Espécies } & \multicolumn{2}{|c|}{ Colpo } & \multicolumn{2}{|c|}{ Endoabertura } & \multicolumn{3}{|c|}{ Camadas da exina } \\
\hline & compr. & larg. & compr. & larg. & exina & nexina & sexina \\
\hline Apeiba tibourbou & 16,0 & 1,5 & 2,0 & 9,3 & 1,5 & 0,8 & 0,7 \\
\hline Corchorus hirsutus & 28,1 & 2,1 & 3,8 & 12,5 & 2,1 & 1,2 & 0,9 \\
\hline Luehea candicans & 36,3 & 3,8 & 2,0 & 18,8 & 1,9 & 1,0 & 0,9 \\
\hline L. conwentsii & 36,4 & 2,5 & 2,3 & 16,4 & 2,1 & 1,1 & 1,0 \\
\hline L. divaricata & 26,0 & 3,0 & 4,0 & 13,0 & 2,2 & 1,2 & 1,0 \\
\hline L. grandiflora & 35,2 & 2,4 & 6,2 & 16,5 & 2,0 & 1,0 & 1,0 \\
\hline L. ochrophylla & 26,8 & 2,3 & 1,6 & 6,7 & 2,3 & 1,2 & 1,1 \\
\hline L. paniculata & 11,0 & 0,8 & 0,8 & 5,5 & 2,1 & 1,1 & 1,0 \\
\hline Triunfetta althaeoides & 46,3 & 3,8 & 4,9 & 16,3 & 2,0 & 1,0 & 1,0 \\
\hline T. grandiflora & 51,4 & 2,9 & 6,5 & 12,9 & 2,2 & 1,2 & 1,0 \\
\hline T. obscura & 42,1 & 3,0 & 6,3 & 16,9 & 2,2 & 1,1 & 1,1 \\
\hline T. rhomboidea & 34,1 & 2,4 & 3,8 & 10,9 & 2,4 & 1,3 & 1,1 \\
\hline
\end{tabular}

\subsection{Triumfetta althaeoides Lam.}

Fig. 2e-f Grãos de pólen grandes, isopolares, prolatos, área polar pequena (Tabs. 1; 3), âmbito subtriangular, 3-colporados (Fig. 2e), colpos longos, estreitos, margem não aparente, membrana ornamentada, endoabertura nitidamente lalongada (Tab. 4), sexina reticulada, heterobrocada, muros estreitos, retos, lisos, baixos, com perfurações, lumens amplos recobertos por fina camada de sexina densamente perfurada. Nexina tão espessa quanto à sexina (Tab. 4).

Os espécimes utilizados para comparação apresentaram apenas os valores da faixa de variação do diâmetro polar dentro dos limites quando comparados com o material padrão. A forma se manteve constante.

A ornamentação de T. althaeoides parece a sexina birreticulada registrada em Hesse et al. (2009).

\subsection{Triumfetta grandiflora Vahl. Fig. 2g-h}

Grãos de pólen grandes, isopolares, prolatos, área polar pequena (Tabs. 1; 3), âmbito subtriangular, 3-colporados (Fig. 2g), colpos longos, estreitos, com margem fina, membrana ornamentada, endoabertura nitidamente lalongada (Tab. 4), sexina microrreticulada, heterobrocada, muros estreitos, retos, lisos, altos (Fig. 2g), sem perfuração, lumens pequenos, sem ornamentação. Nexina ligeiramente mais espessa do que a sexina (Tab. 4). Não foi possível conseguir espécime para comparação.

4.3. Triumfetta obscura A. St.-Hil. Fig. $2 \mathrm{i}-\mathrm{j}$ Grãos de pólen médios a grandes, isopolares, prolatos a subprolatos, área polar pequena (Tabs. 1; 3), âmbito subtriangular, 3-colporados (Fig. 2i), colpos longos, estreitos, margem não aparente, membrana psilada (Fig. 2j), endoabertura nitidamente lalongada (Tab. 4), sexina reticulada, heterobrocada (Fig. 2i), muros estreitos, retos, lisos, baixos, lumens amplos, com microrretículo no interior das malhas do retículo. Nexina tão espessa quanto à sexina (Tab. 4).

Os espécimes utilizados para comparação apresentaram apenas os valores da faixa de variação do diâmetro equatorial dentro dos limites quando comparados com o material padrão. A forma também variou.

4.4. Triumfetta rhomboidea Jacq.

Fig. 2k-1

Os grãos de pólen médios, isopolares, prolatos, área polar pequena (Tabs. 1; 3), âmbito subtriangular, 3-colporados (Fig. 2k), colpos 
longos, estreitos, margem não aparente, membrana ornamentada (Fig. 21), endoabertura nitidamente lalongada (Tab. 4), sexina reticulada, heterobrocada (Fig. 21), muros estreitos, retos, lisos, baixos, lumens amplos, recobertos por fina camada de sexina densamente perfurada. Nexina ligeiramente mais espessa do que a sexina (Tab. 4). Não foi possível conseguir espécime para comparação.

\section{Chave polínica para espécies de Grewioideae ocorrentes no estado do Rio de Janeiro}

1. Cólporos diploporados Apeiba tibourbou

1'. Cólporos com uma única endoabertura.

2. Sexina perfurada no apocolpo e reticulada no mesocolpo.

3. Colpos com costa Luehea grandiflora

3'. Colpos sem costa. Luehea candicans, Luehea conwentzii

2'. Sexina reticulada em toda a superfície.

4. Lumens do retículo com microrretículo no interior das malhas do retículo

4'. Lumens do retículo sem microrretículo no interior das malhas do retículo.

5. Lumens do retículo não recobertos por fina camada de sexina densamente perfurada... Triumfetta grandiflora

5'. Lumens do retículo recobertos por fina camada de sexina densamente perfurada.

6. Colpos com costa Luehea divaricata

6'. Colpos sem costa.

7. Valores do intervalo de confiança a 95\% do diâmetro polar $>60 \mu \mathrm{m}$, comprimento do colpo ca. 46,3 $\mu \mathrm{m}$............................ Triumfetta althaeoides

7'. Valores do intervalo de confiança a 95\% do diâmetro polar $<50 \mu \mathrm{m}$, comprimento do colpo $<45 \mu \mathrm{m}$.

8. Valores do intervalo de confiança a 95\% do diâmetro polar $>42 \mu \mathrm{m}$.

9. Colpos ca. $11 \mu \mathrm{m}$ de comprimento, muros do retículo retos, baixos e alguns lumens com pilos Luehea paniculata

9'. Colpos ca. 26,8 $\mu \mathrm{m}$ de comprimento, muros do retículo sinuosos, altos, lumens sem pilos. Luehea ochrophylla

8'. Valores do intervalo de confiança a 95\% do diâmetro polar $<42 \mu \mathrm{m}$.

10. Valores do intervalo de confiança a $95 \%$ do diâmetro polar $=39,4$ 40,6 $\mu \mathrm{m}$; colpos ca. 28,1 $\mu \mathrm{m}$; muros do retículo largos, sinuosos .. Corchorus hirsutus

10 '. Valores do intervalo de confiança a 95\% do diâmetro polar $=39,7-$ 41,7 $\mu \mathrm{m}$; colpos ca. 34,1 $\mu \mathrm{m}$; muros do retículo estreitos, retos..... Triumfetta rhomboidea

\section{Discussão}

Foram objetos desse estudo os grãos de pólen de 12 espécies subordinadas a quatro gêneros ocorrentes no estado do Rio de Janeiro. A sexina perfurada no apocolpo e reticulada no mesocolpo foi observada apenas em Luehea grandiflora (colpo com costa), L. candicans e L. conwentsii (colpo sem costa). As outras três espécies de Luehea, as quatro espécies de Triumfetta, Apeiba tibourbou e Corchorus hirsutus apresentaram sexina reticulada em toda a superfície. Estas espécies foram separadas na chave polínica elaborada pelas características do lúmen dos retículos (com ou sem microrretículo no interior ou por possuir ou não fina camada de sexina densamente perfurada), pelas dimensões e atributos da abertura ou pelos valores do intervalo de confiança do diâmetro polar. Apeiba tibourbou foi a única espécie analisada no presente estudo a possuir cólporos diploporados.

Colinvaux et al. (1999), publicaram um manual e atlas palinológico da Amazônia, e dentre as espécies analisadas estavam Luehea sp. e Apeiba sp. Foram determinadas pelos autores duas espécies de cada gênero, descritas como 
Tabela 4 - Medidas (em mm) dos grãos de pólen, em vista equatorial, do material de comparação de espécies de Grewioideae $(\mathrm{n}=10)$.

Table 4 - Measurements (in mm) of pollen grain in the equatorial view of comparison material Grewioideae species $(\mathrm{n}=10)$.

\begin{tabular}{|c|c|c|c|c|c|c|}
\hline \multirow{2}{*}{ Espécies } & \multicolumn{2}{|l|}{ DP } & \multicolumn{2}{|l|}{ DE } & \multirow{2}{*}{$\mathbf{P} / \mathbf{E}$} & \multirow{2}{*}{ Forma } \\
\hline & Faixa de variação & $\mathbf{x}$ & Faixa de variação & $\mathbf{x}$ & & \\
\hline \multicolumn{7}{|l|}{ Corchorus hirsutus } \\
\hline Machado, O.X. de B. s.n. & $37,5-45,0$ & 41,3 & $27,5-30,0$ & 27,9 & 1,48 & prolata \\
\hline Occhioni 524 & $37,5-45,0$ & 40,8 & $27,5-32,5$ & 30,5 & 1,34 & prolata \\
\hline \multicolumn{7}{|l|}{ Luehea candicans } \\
\hline Guilherme Siqueira 97 & $47,5-55,0$ & 50,9 & $35,0-40,0$ & 37,5 & 1,35 & prolata \\
\hline \multicolumn{7}{|l|}{ L. conwentsii } \\
\hline Nunes, G.M. s.n. & $40,0-42,5$ & 41,0 & $28,8-32,5$ & 30,6 & 1,33 & prolata \\
\hline Sucre, D. 9914 & $40,0-43,8$ & 41,6 & $27,5-30,0$ & 29,1 & 1,42 & prolata \\
\hline \multicolumn{7}{|l|}{ L. grandiflora } \\
\hline Equipe do H. Florestal s.n. & $48,8-55,0$ & 52,1 & $48,8-60,0$ & 52,9 & 0,98 & oblato-esferoidal \\
\hline \multicolumn{7}{|l|}{ L. paniculata } \\
\hline Sucre, D. 4499 & $40,0-47,5$ & 44,8 & $26,3-35,0$ & 30,3 & 1,47 & prolata \\
\hline Marquete, R. 699 & $40,0-47,5$ & 43,8 & $27,5-32,5$ & 30,5 & 1,43 & prolata \\
\hline \multicolumn{7}{|l|}{ Triumfetta althaeoides } \\
\hline Gomes, A.L. 68 & $52,5-62,5$ & 57,1 & $33,8-37,5$ & 35,9 & 1,59 & prolata \\
\hline \multicolumn{7}{|l|}{ T. obscura } \\
\hline Almeida, J. 1395 & $50,0-55,0$ & 52,8 & $35,0-40,0$ & 36,4 & 1,45 & prolata \\
\hline Carauta, J.P.P. 2008 & $45,0-57,5$ & 53,6 & $32,5-38,8$ & 36,0 & 1,48 & prolata \\
\hline
\end{tabular}

forma 1 e 2, respectivamente. Para as formas 1 e 2 de Luehea sp. (tratada pelos autores), os atributos foram semelhantes àqueles descritos nas espécies aqui estudadas, diferindo apenas quanto à área polar e o âmbito, que para os autores, a área polar é tão larga quanto o grão de pólen e o âmbito é circular. Já as duas espécies de Apeiba sp. (formas 1 e 2) analisadas pelos autores, as características observadas foram as mesmas encontradas aqui para $A$. tibourbou, exceto quanto à presença de diploporos, característica que não foi observada pelos autores. Foi de extrema importância o estudo em microscopia óptica complementado com a eletrônica de varredura, pois permitiu a observação detalhada dos padrões da ornamentação e das aberturas, no caso dos diploporos, foi perfeita a observação desse detalhe tanto em microscopia óptica, quanto em MEV (Fig. 1a-b).

Perveen \& Qaiser (2007) estudaram a flora polínica do Paquistão (Malvaceae-Grewioideae), e com base na ornamentação da exina, foram reconhecidos pelos autores, três tipos polínicos distintos: Tipo Corchorus aestuans, Tipo Corchorus depressus e o Tipo Corchorus tridens. Comparando a espécie de Corchorus aqui analisada, as características observadas pelos autores foram semelhantes com relação ao Tipo Corchorus depressus, com a exina reticulada, já nos outros Tipos descritos pelos autores a exina variou de rugulada-reticulada à rugulada.

Saba (2007) estudou os grãos de pólen de 69 espécies pertencentes a 26 gêneros, representativos das nove subfamílias de Malvaceae, priorizandose, quando possível, táxons que têm ocorrência registrada para a Região Nordeste do Brasil. Dentre elas estudou Corchorus, Heliocarpus, Luehea e Triumfetta (Grewioideae). Para as espécies de Corchorus as características foram semelhantes àquelas aqui descritas para $C$. hirsutus. Já para as espécies de Luehea, os atributos analisados foram 
semelhantes, exceto pela presença de costa em uma das espécies, L. candicans, característica que não foi observada no presente estudo para essa espécie, pois a presença de costa foi observada somente em L. divaricata e L. grandiflora. Para as espécies de Triumfetta, a autora descreveu o âmbito como subcircular e observou a presença de fastígio, características que não foram observadas nas espécies desse gênero aqui analisadas, mesmo em T. althaeoides, uma vez que o âmbito é subtriangular para todas as espécies desse gênero e não foi observada a presença de fastígio.

Mambrín et al. (2010), fizeram análises morfológicas e morfométricas dos grãos de pólen de Corchorus, Heliocarpus, Luehea, Mollia e Triumfetta da região sul da América do Sul. As autoras caracterizaram Corchorus argutus e $C$. hirtus com âmbito subcircular, presença de costa, grãos de pólen zonoaperturados (C. argutus) e a sexina com a mesma espessura do que a nexina. No presente estudo, C. hirsutus, possui o âmbito subtriangular, sem presença de costa, os grãos de pólen não são zonopaerturados e a nexina é mais espessa do que a sexina.

Com relação ao gênero Luehea, Mambrín et al. (2010) descreveram palinologicamente sete espécies: L. candicans, L. conwentzii, L. divaricata, L. fiebrigii, L. grandiflora, L. microcarpa e $L$. paniculata. Dentre elas, só não ocorre no estado do Rio de Janeiro L. fiebrigii e L. microcarpa. Os grãos de pólen são grandes apenas em L. grandiflora, segundo as autoras e, por isso, destaca-se entre as espécies por elas analisadas, porém aqui nesse estudo, os grãos de pólen são grandes tanto em $L$. grandiflora quanto em L. candicans. Já a forma dos grãos de pólen do gênero Luehea é muito variável, podendo ser subesferoidal, subprolata a prolata esferoidal; sendo que, no presente estudo nenhuma das espécies de Luehea estudadas apresentou forma subesferoidal, e L. grandiflora variou de oblatoesferoidal à prolato-esferoidal. Também foi descrito pelas autoras grãos de pólen zonoaperturados em L. divaricata, que aqui não foi descrita essa característica para nenhuma espécie desse gênero, como observado na própria L. divaricata (Fig. 1i-j).

Para finalizar a discussão de Mambrín et al. (2010), as autoras analisaram cinco espécies de Triumfetta (T. bogotensis, T. guaranitica, $T$. obscura, T. rhomboidea e T. semitriloba), sendo que dessas espécies, duas também foram caracterizadas nesse estudo ( $T$. obscura e $T$. rhomboidea). De acordo com as autoras, o âmbito variou de circular a subcircular, com presença de costa, grãos de pólen zonoaperturados apenas em $T$. guaranitica e espessura da exina variável, sendo que, no presente estudo todas as espécies possuem grãos de pólen subtriangulares e não foi observada a presença de costa.

Essas diferenças observadas podem ocorrer devido a uma identificação errônea da espécie, por isso é de extrema relevância utilizar material herborizado devidamente identificado por um especialista na área. Outra possibilidade é com relação à qualidade das imagens, pois as observações dos detalhes da morfologia dos grãos de pólen são bem minuciosas, por isso é essencial utilizar diferentes visões, tanto em vista polar com o corte óptico, quanto em vista equatorial com o detalhe da abertura, bem como as fotomicrografias que devem ter qualidade, tanto em ML (microscopia de luz) quanto em MEV (microscopia eletrônica de varredura), pois a observação dos detalhes da abertura e da ornamentação em MEV tornam mais ricas as descrições, não deixando de observar certos detalhes que são possíveis de serem vistos apenas em microscopia óptica, como é o caso do corte óptico.

William et al. (2013), contribuíram com estudos palinológicos apresentando imagens e breves descrições de 364 taxa da África Ocidental, e dentre as espécies analisadas pelos autores, estavam Corchorus fascicularis e C. trilocularis, onde a primeira foi descrita com poro em forma de losango (largo) e a segunda com poro zonoaperturado. Já a espécie aqui analisada, $C$. hirsutus, não apresentou abertura porada, e sim colporada, sendo os colpos longos e estreitos.

Para Silva et al. (2014), dentre as espécies analisadas no catálogo polínico das plantas usadas por abelhas no campus da USP de Ribeirão Preto, constava Triumfetta rhomboidea, que foi caracterizada pelos autores como grãos de pólen em mônades, médios a grandes, radiais, isopolares, âmbitos circulares, prolatos; tricolporados, com ectoabertura do tipo colpo longo e endoabertura lalongada; a exina com espessura de 1,49 \pm 0,39 (0,93-2,03), com superfície reticulada, heterorreticulada. Em relação à mesma espécie aqui analisada, diferiu apenas o âmbito, que é subtriangular.

Os autores Schüler \& Hemp (2016) publicaram um atlas de pólen e esporos e seus taxa parentais do Monte Kilimanjaro e África Oriental. Nesse atlas, citaram o trabalho de Bayer \& Kubitzki (2003) que tratam sobre os tipos polínicos de Malvaceae, que, segundo eles, 
podem ser divididos em alguns tipos principais: o tipo Grewia, o tipo Tilia, o tipo Helicteres, o tipo Bombax e o tipo Malva. Sendo que, o tipo Grewia é principalmente encontrado dentro da subfamília Grewioideae. Apesar dessa informação dada pelos autores, os mesmos também trataram nesse atlas as espécies de Grewia e Triumfetta como Tiliaceae (Malvaceae).

Schüler \& Hemp (2016) trabalharam com 4 tipos polínicos de Grewioideae: 2 tipos de Grewia (G. bicolor e G. microcarpa) e 2 tipos de Triumfetta (T. brachyceras e $T$. flavescens). Os grãos de pólen do tipo Grewia variaram de prolato a perprolato, geralmente reticulado, característica da maioria das espécies em Grewioideae (segundo os autores). Triumfetta brachyceras e T. flavescens apresentaram grãos de pólen prolatos. No presente estudo foram analisadas espécies apenas de Triumfetta, que também apresentam grãos de pólen prolatos.

Ainda de acordo com os autores, que também abordaram sobre a polinização de Grewioideae referindo-se que, quando as flores são relativamente pequenas, os gêneros são polinizados por abelhas, porém, quando as flores são maiores, estas são polinizadas por vertebrados, como morcegos. Eles fizeram uma comparação com Triumfetta semitriloba, tratada por Collevatti et al. (2000), que apresentam flores visitadas principalmente por abelhas solitárias, embora abelhas sociais, besouros, moscas e borboletas também tenham sido registrados.

Independentemente de serem flores pequenas ou grandes, os polinizadores indicados pelos autores podem transportar com facilidade os grãos de pólen de Grewioideae, devido a sua ornamentação ser reticulada e não psilada, sendo o retículo uma ornamentação padrão de Grewioideae, de acordo com Schüler \& Hemp (2016), o que facilita a adesão ao corpo dos insetos ou pequenos mamíferos.

Vários outros autores trataram palinologicamente de espécies de Malvales, que originalmente era constituída por várias famílias, dentre elas, Malvaceae, Bombacaceae, Tiliaceae e Sterculiaceae. Atualmente, estas famílias, após estudos moleculares, foram organizadas como subfamílias e reunidas em Malvaceae s.l. (Judd \& Manchester 1997; Alverson et al. 1999; Bayer et al. 1999; Nyffeler et al. 2005).

Pelos resultados aqui obtidos pode-se considerar que essa subfamília apresenta atributos polínicos que permitem caracterizar a maioria das espécies ocorrentes no estado do Rio de Janeiro. No entanto, observam-se nos resultados, principalmente pela chave polínica que as espécies Luehea candicans e Luehea conwentzii são palinologicamente semelhantes.

Pode-se considerar pelo estudo elaborado que as características mais relevantes e que permitiram reconhecer, em alguns aspectos, as espécies foram:

- cólporos com duas endoaberturas - apenas em Apeiba tibourbou;

- sexina com microrretículo ou sexina densamente perfurada no lúmen - foram observados apenas nos gêneros Luehea e Triumfetta.

$\mathrm{Na}$ chave polínica elaborada, a maioria das espécies puderam ser separadas pelos atributos palinológicos, exceto Luehea candicans e Luehea conwentzii, logo, dentre 12 espécies ocorrentes no estado do Rio de Janeiro, apenas 2 são semelhantes entre si com relação aos atributos polínicos. Portanto, isso permite considerar a euripolinicidade das espécies aqui estudadas. Acredita-se que, desta forma, o presente estudo fornece dados palinológicos suficientes que podem auxiliar na identificação da quase totalidade das espécies da subfamília Grewioideae que ocorrem no estado do Rio de Janeiro.

\section{Agradecimentos}

Os autores agradecem às bolsas PIBIC e Mestrado concedidas pelos seguintes órgãos de fomento: CNPq, Capes e FAPERJ. Agradecemos também aos herbários, que puderam ceder parte do material para confecção desse trabalho.

\section{Referências}

Alverson WS, Whitlock BA, Nyffeler R, Bayer C \& Baum DA (1999) Phylogeny of the core Malvales: evidence from $n d h f$ sequence data. American Journal of Botany 86: 1474-1486.

APG III (2009) An update of the Angiosperm Phylogeny Group classification for the orders and families of flowering plants. Botanical Journal of the Linnean Society 161: 105-121.

APG IV - Angiosperm Phylogeny Group (2016) An update of the Angiosperm Phylogeny Group classification for the orders and families of flowering plants: APG IV. Botanical Journal of the Linnean Society 181: 1-20.

Barth OM \& Melhem TS (1988) Glossário ilustrado de Palinologia. Ed. Unicamp, Campinas. 75p.

Bayer C, Fay M, Bruijn A, Savolainen V, Morton C, Kubitzki K, Alverson W \& Chase M (1999) Support for an expanded family concept of Malvaceae 
within a recircumscribed order Malvales: a combined analysis of plastid atpb and rbcl DNA sequences. Botanical Journal of the Linnean Society 129: 267-303.

Bayer C \& Kubitzki K (2003) Malvaceae. In: Kubitzki $\mathrm{K}$ (ed.) The families and genera of vascular plants. Malvales, Capparales and non-betalain Caryophyllales. Vol. 5. Springer, Berlin. Pp. 225-311.

Brunken U \& Muellner AN (2012) A new tribal classification of Grewioideae (Malvaceae) based on morphological and molecular phylogenetic evidence. Systematic Botany 37: 699-711.

Colinvaux PA, Oliveira PE \& Patiño JEM (1999) Amazon pollen manual and atlas. Vol. 1. Harwood Academic Publishers, New York, Amsterdam. 330p.

Collevatti RG, Schoereder JH \& Campos LAO (2000) Foraging behavior of bee pollinators on the tropical weed Triumfetta semitriloba: flight distance and directionality. Revista Brasileira de Biologia 60: 29-37.

Erdtman G (1952) Pollen morphology and plant taxonomy-Angiosperms. Almqvist \& Wiksell, Stockholm. 539p.

Hesse M, Halbritter H, Zetter R, Weber M, Buchner R, Frosch-Radivo A \& Ulrich S (2009) Pollen terminology an illustrated handbook. Springer, Wien, New York. 266p.

Mambrín MV, Avanza MM \& Ferrucci MS (2010) Análisis morfológico y morfométrico del polen de Corchorus, Heliocarpus, Luehea, Mollia y Triumfetta (Malvaceae, Grewioideae) en la región austral de América del Sur. Darwiniana 48: 45-58.

Melhem TS, Barros MAVC, Corrêa AMS, MakinoWatanbe H, Capelato MSFS \& Gonçalves-Esteves V
(2003) Variabilidade polínica em plantas de Campos do Jordão (São Paulo, Brasil). Boletim do Instituto de Botânica 16: 16-104.

Perveen A \& Qaiser M (2007) Pollen flora of PakistanMalvaceae-Grewioideae-LII. Pakistan Journal of Botany 39: 1-10.

Punt W, Blackmore S, Nilsson S \& Le Thomas A (2007) Glossary of pollen and spore terminology. Review of Palaeobotany \& Palynology 143: 1-81.

Saba MD (2007) Morfologia polínica de Malvaceae: implicações taxonômicas e filogenéticas. Tese de Doutorado. Universidade Estadual de Feira de Santana, Feira de Santana. 188p.

Salgado-Labouriau ML (1973) Contribuição à palinologia dos cerrados. Academia Brasileira de Ciências, Rio de Janeiro. 291p.

Salgado-Labouriau ML, Vanzolini PE \& Melhem TS (1965) Variation of polar axes and equatorial diameters in pollen grains of two species of Cassia. Grana palynological 6: 166-176.

Silva CI, Evaldt AP, Saraiva AM, Garófalo CA, Queiroz EP, Paulino Neto HF, Castro JP, Wolff JL, Aleixo KP, Faria LB, Caliman MJF, Castro MMN, Groppo M, Bauermann SG \& Fonseca VLI (2014) Catálogo polínico das plantas usadas por abelhas no campus da USP de Ribeirão Preto. Holos, Ribeirão Preto. $153 \mathrm{p}$.

Schüler L \& Hemp AM (2016) Atlas of pollen and spores and their parent taxa of Mt Kilimanjaro and tropical East Africa. Quaternary International 425: 301-386.

William DG, Charlotte SM \& Daniel A (2013) Atlas of the tropical West African pollen flora. Livingstone. Review of Palaeobotany and Palynology 199: $1-135$. 